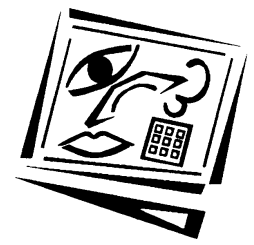

\title{
Pedagogical knowledge representation through concept mapping as a study and collaboration tool in teacher education
}

\author{
Mustafa Koc \\ Suleyman Demirel University
}

\begin{abstract}
This study explored (a) pre-service teachers' perceptions of using concept mapping $(\mathrm{CM})$ in one of their pedagogical courses, (b) the predictive power of such implementation in course achievement, and (c) the role of prior experience with $\mathrm{CM}$, type of mapping, and gender on their perceptions and performances in $\mathrm{CM}$ and achievement. The subjects were 89 pre-service teachers majoring in technical education in Turkey. Each participant developed five concept maps and shared them with classmates. The data sources included assessments of concept maps, midterm exam scores, and student feedback questionnaires. Overall, participants had positive perceptions about $\mathrm{CM}$. They indicated that CM helped them prepare for class lessons and examinations, understand complex issues, and reflect on their (mis)understandings. CM significantly predicted course achievement. Gender, prior experience with $\mathrm{CM}$, and type of mapping were found to be insignificant factors in their perceptions and performances in $\mathrm{CM}$ and in the prediction of achievement.
\end{abstract}

\section{Introduction}

This study contributes to the field of concept maps as cognitive tools, or what Jonassen (1996) calls "mindtools". Research in cognitive science has demonstrated that learning is meaningful when students are active and when they relate new knowledge to relevant concepts they already know (Canas, Hoffman, Coffey \& Novak, 2003). The theoretical framework of such research is based on Ausubel's (1968) assimilation theory of learning, which stresses the importance of individuals' existing cognitive structures in being able to learn new concepts. Inspired by this framework, Novak and Gowin (1984) developed concept mapping (CM) as a way of graphical representation of concepts, based on their research on understanding changes in children's knowledge of science. In parallel with the recent advancements in computer-based visualisation, there has been growing interest in the application of $\mathrm{CM}$ to enhance the quality of teaching and learning in higher education (Hay, Kinchin \& Lygo-Baker, 2008). The present study grew out of such interest and explored the integration of $\mathrm{CM}$ into pre-service teacher education.

\section{Concept mapping and educational usage}

$\mathrm{CM}$ is commonly known as the process of visually linking concepts with propositions. It usually includes construction of concepts enclosed in shapes and propositions of relationships among the concepts indicated by linking words. While constructed by hand using paper and pencil, concept maps can also be developed using computer 
software that simplifies the inclusion and conversion of various colours, shapes, figures, hyperlinks, and audio. Such computer programs support easy manipulation, dynamic linking, publishing, and storage advantages (Canas et al., 2003). Prior research demonstrated that constructing a map with a computer was perceived to be interesting and easier than doing with a paper and pencil (Chang, Sung \& Chen, 2001).

In addition to their application for representing knowledge, concept maps have been used in various ways including to evaluate learners' performance and diagnose misunderstandings (Ruiz-Primo, Schultz \& Shavelson, 1997), design and develop a project, learning materials, and decision making (Coffey, 2007; Hughes \& Hay, 2001), visualise information to foster cognitive processing of retrieving knowledge (Tergan, Keller \& Burkhard, 2006), support problem solving performance (Kinchin, 2000; Okebukola, 1992), and assist navigation, search, and knowledge management in webbased learning environments (Canas et al., 2003). Higher-order mental functions can be developed by engaging in CM. Jonassen (1996) states that CM is a constructivist-based mindtool, "a way of using a computer application program to engage learners in constructive, higher-order, critical thinking about the subjects they are studying" (p. IV). Mackinnon (2006) showed positive impact of CM on students' abilities to formulate arguments, lead effective discussions, and substantiate their conceptual frameworks. Contemporary research indicated that $\mathrm{CM}$ had a positive effect on student achievement (Asan, 2007; Chiou, 2008; Erdogan, 2009; Kwon \& Cifuentes, 2007; Liu, Chen \& Chang, 2010).

\section{Related literature in teacher education}

Researchers employed $\mathrm{CM}$ as a measurement or data analysis tool especially in qualitative studies of teacher education. For example, Lim (2011) utilised CM as a heuristic approach to investigate the underlying structure of Korean student teachers' autobiographical reflections on their professional identity formation. Wilson, Nash and Earl (2010) explored the impact of collaboration between teachers and students with language learning difficulties on teachers' thinking about vocabulary teaching through the use of $\mathrm{CM}$ as measurement of teacher knowledge and understanding. Similarly, Miller et al. (2009) employed CM as a pre-test and a post-test to empirically measure teachers' conceptual growth after participation in a multimedia case-based instruction and recommended CM as a credible and effective research tool. Cabellero, Moreira and Rodriguez (2008) found that CM had great pedagogical potential for mental modelling to explore teachers' internal representations and their possible evolutions.

$\mathrm{CM}$ has also been used for instructional decision making. An experimental study conducted by Blackwell and Pepper (2008) revealed that the construction of concept maps during lesson planning could enhance reflective practices of pre-service teachers when making pedagogical decisions. Cantu, Schroeder and da Silva (2010) used concept maps as a synthesis tool during the collaborative work of secondary school teachers to construct integrated curriculum. They concluded that CM improved curriculum development by fostering the understanding of documents about curriculum, showing the relationships between curricular units, and encouraging the emergence and sharing of innovative ideas during collective debates.

Some research studies have applied CM as an instructional supplement. Schaal (2010) provided pre-service teachers in Germany with pre-defined digital concept maps including hyperlinks to various media (e.g., web sites, animations, video) in order to complement online lectures in a human biology course. He indicated significant 
benefits from frequent use of concept maps for course achievement, and positive motivational aspects (e.g., interest, perceived competence, usefulness). Coutinho and Bottentuit (2008) incorporated CM as a constructivist learning strategy in a postgraduate course on research methods in education. In-service teachers enrolled in this course built concept maps to reflect on course readings and submitted them to class website for the instructor and classmates to leave comments. The analysis of postcourse survey data revealed that teachers perceived $\mathrm{CM}$ as a motivating and convincing tool to understand their own learning. Similarly, Himangshu, Iuli and Venn (2008) used CM to support teaching and learning of elementary teacher candidates in the USA and observed an overall increase in teaching confidence and improvement in student engagement and conceptual understanding. They suggest that using concept maps is a cost-effective strategy for changing the face of teacher education.

Assessment was another area in which the potential of CM in teacher education has been investigated. Oliver and Raubenheimer (2006) incorporated online CM as an alternative assessment tool for distance education courses. The researchers observed student teachers' great interest in CM assignments and recommended using preselected term maps for assessments with reduced level of subjectivity, and open-ended maps for higher-order learning purposes. Buldu and Buldu (2010) investigated the potential contributions of $\mathrm{CM}$ as a formative assessment in teacher education. The results of participant observations, questionnaires and focus group interviews showed that student teachers found CM satisfactory and useful in reducing learning barriers, stimulating reflective thinking, and increasing student involvement and dialogue. The researchers affirmed that $\mathrm{CM}$ could inform both instructors and students about the possible adjustments in their teaching and learning when implemented as formative assessment in the instructional process.

Although these studies revealed promoting results, little is known about what preservice teacher's think about CM tasks. Thus, the present study examined their perceptions about the consequences of using $\mathrm{CM}$ for their education. The originality of the investigation lies in its approach for using $\mathrm{CM}$ as a study and social mediation tool. It enabled pre-service teachers to individually develop concept maps as study aids and then collaboratively share their maps with peers. It was expected that such an implementation may promote student understanding of pedagogical concepts and encourage teacher educators to integrate $\mathrm{CM}$ into instruction.

\section{The role of demographics and type of mapping}

There have been few research studies exploring the role of demographics in CM. While they seem to be consistent with findings of no gender difference in the effect of $\mathrm{CM}$ on learning achievement (Bello \& Abimbola, 1997; Jia, 2007; Lou, Shih, Yen, Tseng \& Wu, 2006), there are contradictory findings in other issues. For example, while female students were found to have a tendency to create less complex maps in one study (Novak \& Musonda, 1991), they produced more complex maps than their male counterparts in other studies (Gerstner \& Bogner, 2009; Martin, Mintzes \& Clavijo, 2000). BouJaiude and Attieh (2003) observed an interaction effect of gender and using $\mathrm{CM}$ as a homework tool, favouring girls over boys, on the knowledge and comprehension level questions in a chemistry achievement test.

Furthermore, few studies have focused on the role of type of mapping. Some indicated no significant differences between paper-based and computer-based CM in concept 
learning (Erdogan, 2009; Hsieh \& Cifuentes, 2006). On the other hand, computer-based $\mathrm{CM}$ that provides learners with an incomplete expert map as a scaffold was found to be more effective for learning than computer-based CM without scaffolding aid, and paper-based CM (Chang, Sung \& Chen, 2001). Furthermore, there have been studies investigating the potential of individual and collaborative CM. Ching and Hsu (2011) observed that online students in well-functioning groups expressed positive comments about CM using Web 2.0 applications (e.g., Webspiration) whereas those in dysfunctional groups preferred to work on their own maps, owing to conflicts among group members and the asynchronous nature of the learning environment. Kwon and Cifuentes (2007) found that students in both individual and collaborative CM groups showed positive attitudes toward CM via Inspiration software, but collaborative group members did not like working as a group. Overall, the findings remain inconclusive and this calls for further research to investigate how demographics or types of mapping interact with $\mathrm{CM}$.

\section{Purpose of the study}

The literature review on $\mathrm{CM}$ indicated that most research has focused primarily on elementary and secondary levels of education, and content-based subjects such as mathematics and science. Therefore, the present study aimed to contribute to developing a research base in the application of $\mathrm{CM}$ within a teacher education context, by exploring (a) pre-service teachers' perceptions of incorporating the CM strategy into one of their pedagogical courses, (b) the predictive power of such implementation in their course achievement, and (c) the role of demographics in their perceptions and performances in CM and course achievement. To fulfil these purposes, the study investigated the following research questions:

1. What are pre-service teachers' perceptions about the integration of the CM strategy into their pedagogical course?

2. Do their perceptions of $\mathrm{CM}$ differ across demographics (gender, prior experience with CM, and type of mapping)?

3. Do their concept map scores differ across demographics?

4. How well do concept map scores, perceptions of CM, and demographics predict their midterm exam scores?

\section{Method}

\section{Setting and participants}

This study took place in the first half of the spring semester 2009 (February to April). The convenience sample included 89 sophomores (second year students) majoring in technical education at a state university in Turkey. Therefore, the participants were pre-service teachers who after graduation will be teaching mechanical, electronic and computer-related design courses mostly in vocational, technical, or secondary schools. Of the 89 participants, with an average age of 21 years $(\mathrm{SD}=0.96), 52(58 \%)$ were male, and $37(42 \%)$ were female.

\section{Concept mapping tasks}

The study was carried out during the pedagogical course, Instructional Planning and Evaluation (IPE), which participants took in the fourth semester of their study. The 
course was taught by the researcher during five consecutive class sessions (45 minutes each) per week. Although the course was taught traditionally using instructional techniques such as lecture, group discussion, and question-answer, the CM strategy was integrated as an alternative learning tool for the purposes of this investigation, which employed CM as a study and social mediation activity as described below.

Table 1 presents the time flow and instruction plan for the study. In the first week, preservice teachers were introduced to the CM strategy as described by Novak and Gowin (1984) and the computer software packages (e.g., Inspiration) available for building concept maps. The researcher first described briefly the concept maps, presented exemplary maps, and explained the procedure for constructing maps. Following this presentation, the researcher, together with students, built a sample concept map about a specific topic of interest using the classroom computer with Smartboard technology. Having completed this training, pre-service teachers were informed about the series of weekly CM assignments that they had to complete until the midterm exam. They were asked to study related chapters using textbooks, the Internet, and other resources in the university library, and then build their own concept maps either by hand or by computer and bring them to the class.

Toward the end of the class sessions, they formed small groups and shared their concept maps with each other. Sharing maps occurred both within and between the groups. This collaborative activity lasted for almost half an hour and facilitated social interaction, which, in turn, enabled students to see and reflect on different representations of the topic. Following this five-week period of instruction, they took the midterm exam. The teaching, $\mathrm{CM}$ activities, and investigations were conducted in the Turkish language with translations into English done by the researcher. The assessment components and associated weightings used to calculate course grade were as follows: CM assignments (20\%), midterm exam (20\%), and final exam (60\%).

Table 1: Study timeline and instruction plan

\begin{tabular}{|c|c|c|}
\hline Week & Instructional topic & Concept mapping task \\
\hline 1 & Concept map training & An example map was built \\
\hline 2 & $\begin{array}{l}\text { Introduction to basic principles of teaching, curriculum } \\
\text { development, instructional design and lesson planning }\end{array}$ & $\begin{array}{l}\text { Map } 1 \text { was developed and } \\
\text { shared with classmates }\end{array}$ \\
\hline 3 & $\begin{array}{l}\text { Designation of instructional objectives based on } \\
\text { taxonomies of learning domains }\end{array}$ & $\begin{array}{l}\text { Map } 2 \text { was developed and } \\
\text { shared with classmates }\end{array}$ \\
\hline 4 & $\begin{array}{l}\text { Selecting and organising course content, instructional } \\
\text { tools, materials and technologies }\end{array}$ & $\begin{array}{l}\text { Map } 3 \text { was developed and } \\
\text { shared with classmates }\end{array}$ \\
\hline 5 & Instructional models and learning theories & $\begin{array}{l}\text { Map } 4 \text { was developed and } \\
\text { shared with classmates }\end{array}$ \\
\hline 6 & Teaching methods and techniques & $\begin{array}{l}\text { Map } 5 \text { was developed and } \\
\text { shared with classmates }\end{array}$ \\
\hline 7 & Midterm exam & \\
\hline
\end{tabular}

For their CM assignments, pre-service teachers were instructed to select the concepts that they thought were most representative of the topic. They were encouraged to use cartoons, comics, pictures, or other visual attributes in their maps, provided that they considered them beneficial for better comprehension of the content. They were also urged to include relevant concepts that they had learned previously so that they could engage in meaningful learning by explicitly making connections between new and existing knowledge. Almost half of the students (48\%) developed their maps on the computer and used Inspiration and word processing software. 


\section{Data sources and instruments}

The research design was descriptive and predictive in nature and based on quantitative data. In order to answer the research questions outlined earlier, data were collected from multiple sources, including (a) assessments of concept maps built by pre-service teachers, (b) midterm exam scores, and (c) concept map feedback questionnaires.

Each of the maps was scored based on a widely used structural scoring rubric developed by Novak and Gowin (1984). The rubric evaluates each map based on the following four components: (a) one point for each meaningful proposition, (b) five points for each valid level of hierarchy, (c) ten points for each crosslink, and (d) one point for each example. A proposition involves two concept nodes connected with linking words and represents the relationship between the concepts. The number of propositions demonstrates the extent of a domain of knowledge. Hierarchy refers to the organisation of concepts in the order of generalisation to specification and represents the differentiation of concepts. A crosslink is a meaningful proposition between different segments of the hierarchy and represents the reconciliation of concepts. An example is a proposition between a concept and its specific events or objects indicated by the linking words "e.g." (Novak \& Gowin, 1984). The scores for each of these components were compiled to produce a total score for each map. After scoring all maps, a composite variable was created by summing up the scores of five concept maps for each student. Figure 1 illustrates an example of a pre-service teacher's concept map along with the scoring information.

To establish inter-rater reliability, the researcher collaborated with a colleague who had at least five years of experience in both teacher education and the use of concept maps. Both independently scored a subset of maps for the first CM assignment. The intra-class correlation coefficient was computed as $0.93(\mathrm{p}<0.01)$ indicating a good level of agreement. Thereafter, the researcher scored the remaining concept maps.

The midterm exam comprised 20 multiple-choice questions addressing the pedagogical content taught (see Appendix A for sample questions). Some items were adapted from the questions that were asked at the "educational sciences" section of the Public Personal Selection Exam (KPSS) in previous years. KPSS is a centralised, standardised, and nationwide examination administered by the Student Selection and Placement Center (OSYM) in Turkey. To be appointed as teachers in public schools, graduates of teacher education programs must take the "educational sciences" section of this exam that tests their pedagogical knowledge. The remaining items were developed by the researcher to assess students' conceptual understanding of the content. Students earned five points for each correct answer, and their total scores out of 100 points were used as an indicator of their achievement. The higher the score, the more successful the student was in the course. The Kuder-Richardson (KR-20) reliability coefficient for the midterm test was 0.79 for this study.

Moreover, a small questionnaire form was distributed to participants after the fourth CM assignment and was collected as an attachment to their last concept maps. The instrument had two parts. In the first part, participants were asked to indicate their demographic information (e.g., age, gender), whether they had prior experience with $\mathrm{CM}$, and how they developed their concept maps (by hand or by computer). The second part included eight perceptional statements about their learning experience with the integration of CM strategy (see Table 2). These items were adapted from the 
related studies in the literature (e.g., Chiou, 2008; Kwon \& Cifuentes, 2007). Participants were asked to rate each item by using a five-point Likert scale ranging from "strongly disagree" (1) to "strongly agree" (5). Cronbach's alpha reliability coefficient for these perceptional items was 0.86 for the study sample. An optional open-ended item was also included at the end of the questionnaire form for those participants who would like to express any further thoughts on CM activities.

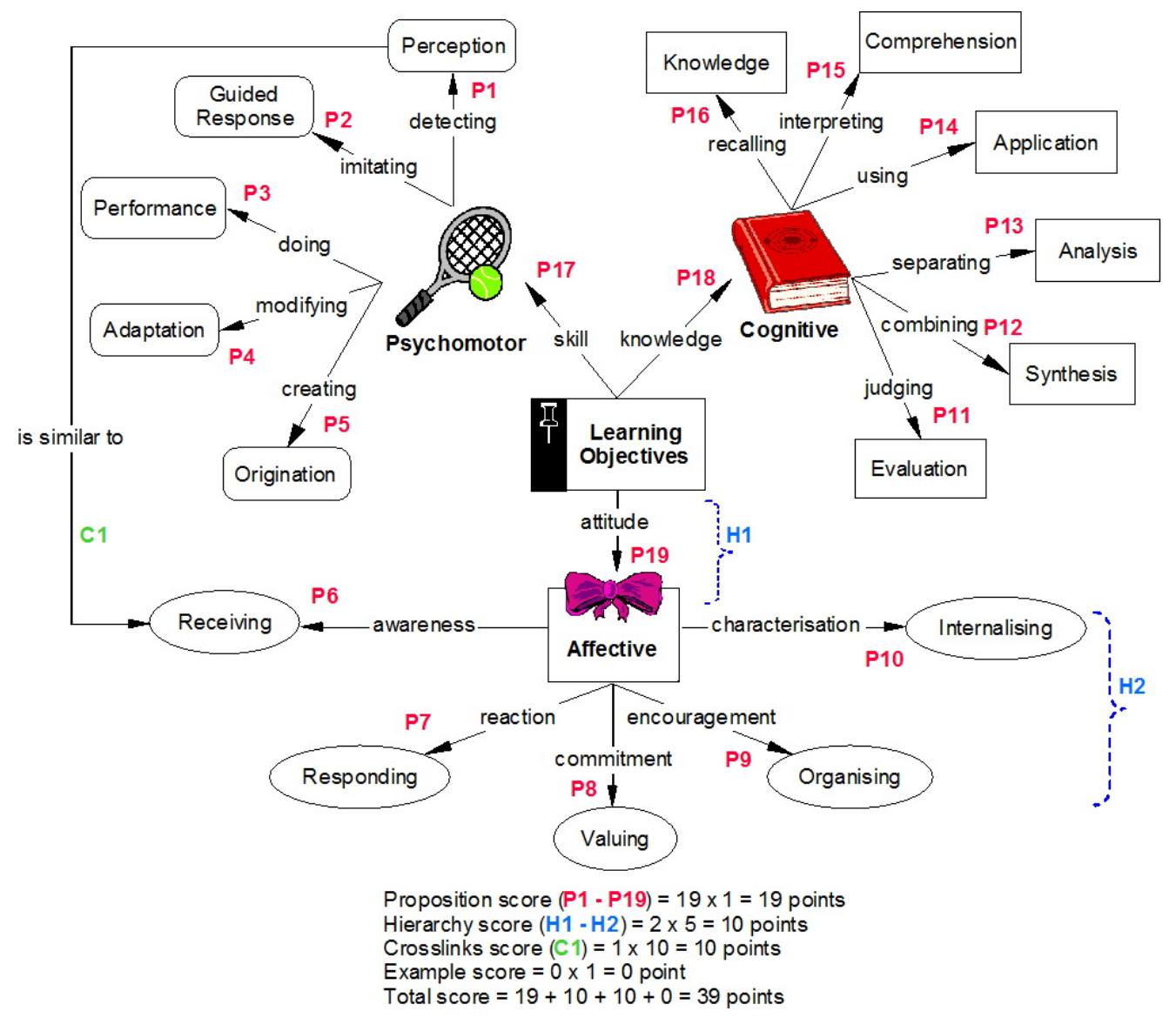

Figure 1: Example of a pre-service teacher's concept map with scoring information

\section{Data analysis}

Descriptive statistical indices including frequency analysis, central tendency measures, and standard deviations were calculated for the examination and presentation of the data. For the comparisons of students' perceptions and concept map scores across demographics, independent t-tests were conducted upon ascertaining that both the normality and homogeneity of variance assumptions were met. Multiple regression analysis was employed to examine the relationship between course achievement and $\mathrm{CM}$ performances, perceptions about $\mathrm{CM}$, prior experience with $\mathrm{CM}$, type of mapping, and gender. 


\section{Results of the study}

Generally speaking, the evidence suggested that pre-service teachers enjoyed and appreciated the implementation of the CM strategy. They reported relatively favourable perceptions that could be classified into three main categories: the use of $\mathrm{CM}$ as a preparation/study aid, cognitive contributions of $\mathrm{CM}$ to better comprehension, and benefits of sharing concept maps. Table 2 reports descriptive statistics for the ratings of perceptional statements germane to $\mathrm{CM}$ activities.

Table 2: Descriptive statistics for perceptions about $\mathrm{CM}$ strategy $(\mathrm{N}=89)$

\begin{tabular}{|l|l|c|c|}
\hline \multirow{2}{*}{ Preparation } & Statement & Mean & SD \\
\cline { 2 - 4 } & CM assignments prepare me well for class sessions & 4.16 & 0.93 \\
\cline { 2 - 4 } $\begin{array}{l}\text { Comprehen } \\
\text { sion }\end{array}$ & Visualisation concretises discrete concepts in an easily tangible way & 3.91 & 1.04 \\
\cline { 2 - 4 } & CM provides me with better understanding of complex issues & 3.93 & 0.95 \\
\cline { 2 - 4 } & CM facilitates making interconnections among (sub)chapters & 3.71 & 0.98 \\
\cline { 2 - 4 } & It is worthwhile developing maps for other courses & 0.98 \\
\hline \multirow{2}{*}{$\begin{array}{l}\text { Collabor- } \\
\text { ation }\end{array}$} & Sharing maps with friends helps me address my misunderstandings & 3.72 & 0.93 \\
\cline { 2 - 4 } & Sharing maps helps me identify the relations amongst the concepts & 3.71 & 1.16 \\
\hline
\end{tabular}

Around seven out of ten perceived that CM assignments effectively helped them get ready for classroom lectures and prepared them well for the exams administered throughout the IPE course. Two thirds of the participants reported that visual demonstrations in the maps solidified complicated or discrete concepts in an easily tangible manner, and that $\mathrm{CM}$ facilitated better understanding of complex issues and making interconnections among the contents of (sub)chapters covered in the course. Regarding collaborative usage and its implications, more than half perceived that sharing concept maps with peers helped them resolve their misconceptions and understand the relations that they could not grasp on their own while reading the text. On the whole, the mean scores showed that pre-service teachers' perceptions about the $\mathrm{CM}$ activities were positive.

On the other hand, through the open-ended item in the questionnaire, some participants referred to two challenges that they experienced during the $\mathrm{CM}$ assignments. First, they expressed that building a concept map every week was frustrating, and instead, they suggested building maps once every two to three weeks. Second, they had difficulties in finding appropriate linking words or phrases to form correct propositions between the concepts. Here are some illustrative comments supporting these observations:

It is very different and more challenging than classic homework assignments (writing summaries, preparing presentations, etc.) that we were used to doing. I had much fun being involved in my own learning and proud of my concept maps. However, I am also concerned about the time that it takes for me to find the silent concepts in the chapters and to synthesise them in a meaningful way... I think that building maps in every week eventually become difficult and boring...It would be better and easier to utilise concept mapping in every two or three weeks.

My hassle moments with concept mapping related to finding appropriate linking words to connect the nodes [concepts]. In fact, I just combined some of them without the words. They [propositions] were not always grammatically correct or complete when one read from the first concept to the second one. Sometimes, I used phrases and short statements to link the nodes but then the overall map looked complicated. 
The most difficult part for me is to link the concepts with connecting words. Most of the time the connecting words should be verbs since the concepts are subjects or objects. Thus, when the verb is in the middle of the concepts, the whole statement becomes an inverted sentence. To overcome this problem, I used a prefix such as "-a, e, -na" in the linking words. For example, for the statement "Ders planı ögreme çiktılarını içerir" [Lesson plan includes learning outcomes], I used "-nı içerir" as linking words to make a grammatically formal statement "Ders planı -nı içerir ögrenme çıtıları".

The word order like "first concept-linking word-second concept" is not always grammatically correct as it constitutes an odd sentence in our language. However, if you read in the order "first concept-second concept-linking word", then it could be a meaningful statement. In my opinion, this [word order] is not of much importance as long as the constructor of the map understands the relationship that he/ she would like to represent.

It was difficult at first but then got easier. I believe that the difficulty is due to our habit of memorising verbal concepts. Mapping is an effort-demanding task because you need to become quite familiar with the content so that you can construct a meaningful map that represents the big picture of the topic. Of course, this takes a lot of time and becomes tough especially when we have several homework and projects due at the same time... but it was nice not being foreign to what instructor taught about in the lectures.

A $2 \times 2 \times 2$ multivariate analysis of variance (MANOVA) was conducted using gender, prior experience with $\mathrm{CM}$, and type of mapping as independent variables with overall $\mathrm{CM}$ perception score and concept map score as dependent variables. This analysis was employed in order to control the Type I error rate due to the multiple dependent variables simultaneously compared across the independent variables. The mean scores, standard deviations and associated statistics for the main effects were given in Table 3. The overall MANOVA test failed to indicate significant main effect of gender (Wilks' lambda $=0.98, \mathrm{~F}[2,82]=1.06, \mathrm{p}>0.05)$, prior experience with CM (Wilks' lambda $=0.97, \mathrm{~F}[2,82]=1.40, \mathrm{p}>0.05$ ), and type of mapping (Wilks' lambda $=0.95, \mathrm{~F}[2$, $82]=2.25, \mathrm{p}>0.05)$. Hence, there was no need to conduct univariate analyses for each dependent variable. There were also no significant two-way and three-way interaction effects of independent variables.

Table 3: MANOVA results for the main effects of gender, prior experience, and type of mapping on perception and concept map score

\begin{tabular}{|c|c|c|c|c|c|c|c|c|c|}
\hline \multirow{2}{*}{\multicolumn{2}{|c|}{ Factor }} & \multirow[b]{2}{*}{$\mathrm{N}$} & \multicolumn{2}{|c|}{ Perception score } & \multicolumn{2}{|c|}{ Concept map score } & \multirow{2}{*}{$\begin{array}{l}\text { Wilks' } \\
\text { lambda }\end{array}$} & \multirow{2}{*}{$\mathrm{F}$} & \multirow{2}{*}{$\mathrm{p}$} \\
\hline & & & Mean & SD & Mean & $\mathrm{SD}$ & & & \\
\hline \multirow[t]{2}{*}{ Gender } & Male & 52 & 3.88 & 0.65 & 104.75 & 32.51 & \multirow[t]{2}{*}{0.98} & \multirow[t]{2}{*}{1.06} & \multirow[t]{2}{*}{0.35} \\
\hline & Female & 37 & 3.77 & 0.79 & 112.43 & 31.19 & & & \\
\hline \multirow{2}{*}{$\begin{array}{l}\text { Prior experi- } \\
\text { ence with } \mathrm{CM}\end{array}$} & Yes & 12 & 3.86 & 0.49 & 94.50 & 16.61 & \multirow[t]{2}{*}{0.97} & \multirow[t]{2}{*}{1.40} & \multirow[t]{2}{*}{0.25} \\
\hline & No & 77 & 3.83 & 0.74 & 110.04 & 33.37 & & & \\
\hline \multirow{2}{*}{$\begin{array}{l}\text { Type of } \\
\text { mapping }\end{array}$} & By computer & 43 & 3.97 & 0.56 & 109.28 & 29.80 & \multirow[t]{2}{*}{0.95} & \multirow[t]{2}{*}{2.25} & \multirow[t]{2}{*}{0.11} \\
\hline & By hand & 46 & 3.70 & 0.80 & 106.70 & 34.24 & & & \\
\hline
\end{tabular}

A multiple linear regression analysis was conducted to make predictions about preservice teachers' achievement in the IPE course. Midterm exam score (mean $=63.54$, $\mathrm{SD}=10.87$ ) was treated as the criterion variable whilst concept map score (mean = $107.94, \mathrm{SD}=32.01)$, perceptions of $\mathrm{CM}($ mean $=3.83, \mathrm{SD}=0.71)$, prior experience with $\mathrm{CM}$, type of mapping, and gender were entered as predictor variables. Dummy coding was used for the categorical variables (e.g., gender). Table 4 demonstrates excerpts 
from SPSS output for this analysis. The model included only concept map score as a significant predictor $(\beta=0.52, \mathrm{t}=5.54, \mathrm{p}<0.01)$ and accounted for $31 \%$ of the variance in midterm exam score $\left(\mathrm{R}^{2}=0.31, \mathrm{~F}(5,83)=7.29, \mathrm{p}<0.01\right)$. The model predicts that preservice teachers with higher map scores are likely to score higher on the midterm exam.

Table 4: Regression analysis of midterm exam score

\begin{tabular}{|l|c|c|c|c|c|}
\hline \multicolumn{1}{|c|}{ Predictor variables } & $\mathrm{B}$ & $\mathrm{SE}$ & $\beta$ & $\mathrm{t}$ & $\mathrm{p}$ \\
\hline (Constant) & 41.33 & 6.56 & & 6.30 & 0.00 \\
\hline Concept map score & 0.18 & 0.03 & 0.52 & 5.54 & 0.00 \\
\hline Perceptions of CM & 1.52 & 1.44 & 0.10 & 1.06 & 0.29 \\
\hline Prior experience with CM & 0.47 & 2.98 & 0.02 & 0.16 & 0.88 \\
\hline Type of mapping & -3.12 & 2.05 & -0.14 & -1.52 & 0.13 \\
\hline Gender & -2.18 & 2.08 & -0.10 & -1.05 & 0.30 \\
\hline $\begin{array}{l}\text { Note: } \mathrm{R}^{2}=0.31(\mathrm{p}<0.01) . \mathrm{B}=\text { Unstandardised coefficients, } \\
\beta=\text { Standardised coefficients, SE Standard error }\end{array}$ \\
\hline
\end{tabular}

\section{Discussion and conclusion}

Having found that the regression was significant, the study suggests that students with high quality concept maps are more likely to have higher course achievement. Comprehension and retention of materials in conceptual courses are likely to be associated with students' cognitive processing of information and their system of concept formation. According to the Ausebelian view of human cognitive processes, this system includes an understanding of characteristics of concepts and how they are logically interconnected. As can be observed from the participants' perceptions, this study reveals that CM can facilitate such processes, which, in turn, as shown by the regression analysis, is associated with student achievement. Similar findings were reported in previous research studies on various subjects (Asan, 2007; Chiou, 2008; Erdogan, 2009; Kwon \& Cifuentes, 2007; Liu, Chen \& Chang, 2010; Schaal, 2010). Therefore, teacher educators should try to provide pre-service teachers with more opportunities of constructing concept maps in their pedagogical courses.

In accordance with the participants' perceptions, constructing maps before class lessons seems to yield the greatest benefits for planning and studying in advance. Consistent with research in different contexts (BouJaiude \& Attieh, 2003; Buldu \& Buldu, 2010; Coutinho \& Bottentuit, 2008), concept maps were perceived as useful study tools that could be incorporated into higher education. Likewise, the present study implied that concept maps could be useful in preparation for classes and examinations. Supporting Novak and Gowin's (1984) arguments, these findings suggest that graphical demonstration of concepts and the relationships between them has potential for assisting memory and recall, as most humans have a higher capacity for recalling visual images than specific verbal details. Participants' positive perceptions about $\mathrm{CM}$ as a preparation aid for exams and CM's significant prediction of exam score suggest that the CM strategy can be incorporated into the preparation courses for centralised examinations (e.g., KPSS etc.).

Based on the analysis of participants' perceptions, the present study supports the view that $\mathrm{CM}$ can facilitate better conceptual understanding of discrete or perplexing issues and the interrelations among them, when the learner incorporates visual aids (Hay, Kinchin \& Lygo-Baker, 2008). Participants perceive that enhancing concept maps with visual aids is important for a better and deeper understanding of complex information 
that may not be easily grasped by just reading or listening. Similarly, visual representation has been shown to enhance the cognitive process of managing and retrieving knowledge and task-related information (Tergan, Keller \& Burkhard, 2006). Buldu and Buldu (2010) also reported that pre-service teachers perceived visualising learning through $\mathrm{CM}$ as helpful for improving their comprehension. Thus, teacher educators can use CM to visualise complex and abstract concepts in their courses.

The study supports philosophical notions of social constructivist learning, because preservice teachers reported that sharing maps with peers not only provided clarification of misconceptions but also fostered communicating and understanding of different perspectives and interpretations of the content. This indicates that sharing maps can engage learners in social interaction with others and create a "zone of proximal development" (Vygotsky, 1978) in which learners can negotiate on shared meanings and perform better with the assistance of others. Buldu and Buldu (2010) observed that student teachers enjoyed sharing concept maps with their friends in small groups and thought the development of collaborative maps was more effective than individual ones. It is important to highlight that the present study employed collaboration as a way of sharing individually-constructed maps. However, several studies showed that students who collaboratively constructed maps did not out-perform those who individually constructed maps on a comprehension test and did not enjoy working in a group (e.g., Kwon \& Cifuentes, 2007). Ching and Hsu (2011) found that students in dysfunctional groups tended to not value collaborative CM, which emphasised the need for integration of both a shared goal (group grading) and individual accountability (individual grading) to improve collaborative knowledge construction. Overall, further research is needed to investigate the consequences of various ways and time of scaffolding collaboration during CM activities.

None of the demographic variables had significant effects on the perceptions and performances in CM. Also, they failed to predict course achievement. That is, perceived benefits and the level of performance in CM were independent of whether pre-service teachers constructed paper-based or computer-based maps, were male or female, or were novice or veteran mappers. This suggests that the CM strategy may have promoted equally both male and female pre-service teachers' cognitive processing and externalisation of knowledge structures. Hence, this study supports the consistent result in the literature showing no gender effects on learning with CM (Bello \& Abimbola, 1997; Jia, 2007; Lou, Shih, Yen, Tseng \& Wu, 2006). Furthermore, the results recommend that the $\mathrm{CM}$ strategy can also be integrated successfully into teacher education programs in which students do not have prior experience with $\mathrm{CM}$ and access to computers. Consistently, former studies revealed that both paper-based and computer-based CM methods produced positive effects on concept learning and attitudes toward $\mathrm{CM}$, but there were no significant differences between the two methods (Erdogan, 2009; Hsieh \& Cifuentes, 2006).

This research reveals crucial practical implications for future implementations of CM. The findings indicated that having pre-service teachers construct maps every week might become an overwhelming or frustrating experience. Since mapping takes a considerable amount of time and effort, excessive usage might ruin the merits of this instructional activity. Oliver and Raubenheimer (2006) and Buldu and Buldu (2010) reported similar findings and suggested that students should be assigned manageable maps covering several weeks of content. Also, participants in the present study complained about the difficulty of finding appropriate connective terms to state the relationships among the concepts. Further analysis of their initial maps and several 
written comments in the questionnaire revealed that such a difficulty could stem from students' struggle with applying the grammatical principles of the Turkish language. In the maps developed in the English language, connective terms are usually in the form of a verb, and the sequence of noun-verb-noun can form a complete and meaningful sentence. However, this is not always possible in the Turkish language, since the word order is generally subject-object-verb in simple sentences. In the present study, this problem was solved by informing students that the propositions between concepts do not have to create grammatically correct sentences and that the connective words can be any type of word or phrase as long as they represent the relationship between the concepts. For more fruitful outcomes, future implementations in similar linguistic settings should consider this concern.

In closing, it is important to acknowledge that this study has several limitations. Firstly, it is descriptive and correlational in nature. The significant prediction of achievement from CM does not necessarily imply that the latter causes the former. However, the results are promising and pointing to further research under controlled conditions (e.g., experimental design) to ensure the effect of concept mapping. Secondly, the study partly rests upon self-reported measures, due to the limited resources and the complex nature of observing cognitive functions. Thus, the generalisability of the results is limited.

\section{References}

Asan, A. (2007). Concept mapping in science class: A case study of fifth grade students. Educational Technology E Society, 10(1), 186-195. http:/ / ifets.info/journals/10_1/17.pdf

Ausubel, D. P. (1968). Educational psychology: A cognitive view. New York: Holt, Rinehart and Winston.

Bello, G. \& Abimbola, I. O. (1997). Gender influence on biology students' concept mapping ability and achievement in evolution. Journal of Science Teaching and Learning, 3(1\&2), 8-17. [verified 24 Apr 2012] http: / / www.unilorin.edu.ng/publications/abimbola/GENDER\%20 INFLUENCE\%20ON\%20BIOLOGY\%20STUDENTS.htm

Blackwell, S. \& Pepper, K. (2008). The effect of concept mapping on preservice teachers' reflective practices when making pedagogical decisions. The Journal of Effective Teaching, 8(2), 77-93. http:/ / uncw.edu/cte/et/articles/Vol8_2/Blackwell.htm

BouJaiude, S. \& Attieh, M. (2003). The effect of using concept maps as study tools on achievement in chemistry. Paper presented at the Annual Meeting of the National Association of Research in Science Teaching. Philadelphia, USA. [verified 1 Apr 2012] http: / / www.eric.ed.gov/ PDFS / ED477305.pdf

Buldu, M. \& Buldu, N. (2010). Concept mapping as a formative assessment in college classrooms: Measuring usefulness and student satisfaction. Procedia Social and Behavioral Sciences, 2(2), 2099-2104. http:/ / dx.doi.org/10.1016/j.sbspro.2010.03.288

Cabellero, C., Moreira, M. A. \& Rodriguez, B. L. (2008). Concept mapping as a strategy to explore teachers' mental representations about the universe. In A. J. Canas, P. Reiska, M. Ahlberg \& J. D. Novak (Eds.), Proceedings of the Third International Conference on Concept Mapping. Helsinki, Finland. [viewed 1 Apr 2012] http: / / cmc.ihmc.us/cmc2008papers/ cmc2008-p108.pdf

Canas, A., Hoffman, R., Coffey, J. \& Novak, J. (2003). A summary of literature review pertaining to the use of concept mapping techniques and technologies for education and performance support. Pensacola, FL: Institute for Human and Machine Cognition. [verified 1 Apr 2012] 
http: / / www.ihmc.us/ users / acanas / Publications / ConceptMapLitReview / IHMC\%20Literat ure $\% 20$ Review $\% 20$ on $\% 20$ Concept $\% 20$ Mapping.pdf

Cantu, E., Schroeder, N. \& da Silva, D. Z. P. (2010). Using concept maps as a synthesis tool to construct integrated curriculum. In J. Sanchez, A. J. Canas \& J. D. Novak (Eds.), Proceedings of the Fourth International Conference on Concept Mapping. Vina del Mar, Chile. [viewed 1 Apr 2012] http:/ / cmc.ihmc.us/cmc2010papers/cmc2010-a9.pdf

Chang, K. E., Sung, Y. T. \& Chen, S. F. (2001). Learning through computer-based concept mapping with scaffolding aid. Journal of Computer Assisted Learning, 17(1), 21-33. http: / / dx.doi.org/10.1111/j.1365-2729.2001.00156.x

Ching, Y.-H. \& Hsu, Y.-C. (2011). Design-grounded assessment: A framework and a case study of Web 2.0 practices in higher education. In J. Waycott \& J. Sheard (Eds), Assessing students' Web 2.0 activities in higher education. Australasian Journal of Educational Technology, 27(Special issue, 5), 781-797. http:/ / www.ascilite.org.au/ajet/ ajet27/ ching.html

Chiou, C. (2008). The effect of concept mapping on students' learning achievements and interests. Innovations in Education and Teaching International, 45(4), 375-387. http: / / dx.doi.org/10.1080/14703290802377240

Coffey, J. W. (2007). A meta-cognitive tool for courseware development, maintenance, and reuse. Computers \& Education, 48(4), 548-566. http:/ / dx.doi.org/10.1016/j.compedu.2005.03.008

Coutinho, C. P. \& Bottentuit, J. B. (2008). Using concept maps with postgraduate teachers in a web-based environment: An exploratory study. In Proceedings of the Workshop on Cognition and the Web: Information Processing, Comprehension and Learning (pp.139-145). Granada, Spain. [viewed 1 Apr 2012]

http: / / repositorium.sdum.uminho.pt/ bitstream/1822/7811/1/Final\%2520Formatado.pdf

Erdogan, Y. (2009). Paper-based and computer-based concept mappings: The effects on computer achievement, computer anxiety and computer attitude. British Journal of Educational Technology, 40(5), 821-836. http:/ / dx.doi.org/10.1111/j.1467-8535.2008.00856.x

Gerstner, S. \& Bogner, F. X. (2009). Concept map structure, gender and teaching methods: An investigation of students' science learning. Educational Research, 51(4), 425-438. http: / / dx.doi.org/10.1080/00131880903354758

Hay, D., Kinchin, I., \& Lygo-Baker, S. (2008). Making learning visible: The role of concept mapping in higher education. Studies in Higher Education, 33(3), 295-311. http: / / dx.doi.org/ 10.1080/03075070802049251

Himangshu, S., Iuli, R. J. \& Venn, M. (2008). Impact concept mapping has on pre-service teachers understanding of science content knowledge and development of their science pedagogy. In A. J. Canas, P. Reiska, M. Ahlberg \& J. D. Novak (Eds.), Proceedings of the Third International Conference on Concept Mapping. Helsinki, Finland. [viewed 1 Apr 2012] http: / / cmc.ihmc.us/ cmc2008papers/ cmc2008-p341.pdf

Hsieh, Y. J. \& Cifuentes, L. (2006). Student-generated visualization as a study strategy for science concept learning. Educational Technology \& Society, 9(3), 137-148. http://ifets.info/journals/9_3/12.pdf

Hughes, G. \& Hay, D. (2001). Use of concept mapping to integrate the different perspectives of designers and other stakeholders in the development of e-learning materials. British Journal of Educational Technology, 32(5), 557-569. http: / / dx.doi.org/10.1111/1467-8535.00225

Jia, J. (2007). The effects of concept mapping as advance organizers in instructional designs for distance programs. Unpublished doctoral dissertation, Wayne State University, USA.

Jonassen, D. H. (1996). Computers in the classrooms: Mindtools for critical thinking. Englewood Cliffs, NJ: Prentice Hall. 
Kinchin, I. M. (2000). Concept mapping in biology. Journal of Biological Education, 34(2), 61-68. http: / / dx.doi.org/10.1080/00219266.2000.9655687

Kwon, S. Y. \& Cifuentes, L. (2007). Using computers to individually-generate vs. collaboratively generate concept maps. Educational Technology \& Society, 10(4), 269-280. http: / / ifets.info/journals/10_4/23.pdf

Lim, H. (2011). Concept maps of Korean EFL student teachers' autobiographical reflections on their professional identity formation. Teaching and Teacher Education, 27(6), 969-981. http: / / dx.doi.org/10.1016/j.tate.2011.05.001

Liu, P., Chen, C. \& Chang, Y. (2010). Effects of a computer-assisted concept mapping strategy on EFL college students' English reading comprehension. Computers E Education, 54(2), 436-445. http:/ / dx.doi.org/10.1016/j.compedu.2009.08.027

Lou, S. J., Shih, R. C., Yen, R. C., Tseng, K. H. \& Wu, H. L. (2006). A study of integrating concept mapping into computer assisted instruction in biology. WSEAS Transactions on Computers, 5(5), 1080-1087.

Mackinnon, G. (2006). Contentious issues in science education: Building critical thinking patterns through two-dimensional concept mapping. Journal of Educational Multimedia and Hypermedia, 15(4), 433-445. http: / / www.editlib.org/p/19840

Martin, B. L., Mintzes, J. J. \& Clavijo, I. E. (2000). Restructuring knowledge in biology: Cognitive processes and metacognitive reflections. International Journal of Science Education, 22(3), 303323. http:/ / dx.doi.org/10.1080/095006900289895

Miller, K. J., Koury, K. A., Fitzgerald, G. E., Hollingsead, C., Mitchem, K. J., Tsai, H. et al. (2009). Concept mapping as a research tool to evaluate conceptual change related to instructional methods. Teacher Education and Special Education, 32(4), 365-378. http: / / dx.doi.org/10.1177/0888406409346149

Novak, J. D. \& Gowin, B. (1984). Learning how to learn. Cambridge, NY: Cambridge University Press.

Novak, J. D. \& Musonda, D. (1991). A twelve-year longitudinal study of science concept learning. American Educational Research Journal, 28(1), 117-153. http: / / dx.doi.org/10.3102/00028312028001117

Okebukola, P. A. (1992). Can good concept mappers be good problem solvers in science? Research in Science and Technological Education, 10(2), 153-170. http: / / dx.doi.org/10.1080/0263514920100204

Oliver, K. \& Raubenheimer, D. (2006). Lessons learned from unstructured concept mapping tasks. In A. J. Canas \& J. D. Novak (Eds.), Proceedings of the Second International Conference on Concept Mapping (Vol. I, pp.351-358). San Jose, Costa Rica: Universidad de Costa Rica. [verified 01 Apr 2012] http:/ / kevoliver.com/pdf/ cmc2006.pdf

Ruiz-Primo, M. A., Schultz, S. E. \& Shavelson, R. J. (1997). Concept map-based assessment in science: Two exploratory studies. Los Angeles, CA: CRESST. [verified 01 Apr 2012] http: / / www.cse.ucla.edu/ products / reports / TECH436.pdf

Schaal, S. (2010). Enriching traditional biology lectures-digital concept maps and their influence on achievement and motivation. World Journal on Educational Technology, 2(1), 42-54. http: / / www.world-education-center.org/index.php/wjet/article/view / 162/pdf_9

Tergan, S. O., Keller, T. \& Burkhard, R. (2006). Integrating knowledge and information: Digital concept maps as a bridging technology. Information Visualization, 5(3), 167-174. http:/ / dx.doi.org/ 10.1057/ palgrave.ivs.9500132

Vygotsky, L. (1978). Mind in society: The development of higher psychological processes. Cambridge, MA: Harvard University Press. 
Wilson, G., Nash, M. \& Earl, G. (2010). Supporting students with language learning difficulties in secondary schools through collaboration: The use of concept maps to investigate the impact on teachers' knowledge of vocabulary teaching. Child Language Teaching and Therapy, 26(2), 163-179. http: / / dx.doi.org/10.1177/0265659010368749

\section{Appendix: Sample questions from the midterm exam}

1. Which level of the cognitive domain is supported when the students are requested to write authentic essay about the effects of globalisation on education?
a. Comprehension
b. Synthesis
c. Analysis
d. Knowledge
e. Evaluation

2. According to some learning theories, knowledge is: (I) objective and independent from the learner, (II) subjective and constructed by the learner and (III) objective and related to the learner's previous knowledge. Please indicate the correct matching below.

$\begin{array}{lccc} & \text { Behaviorism } & \text { Cognitivism } & \text { Constructivism } \\ \text { a. } & \text { III } & \text { II } & \text { I } \\ \text { b. } & \text { II } & \text { III } & \text { I } \\ \text { c. } & \text { I } & \text { III } & \text { II } \\ \text { d. } & \text { II } & \text { I } & \text { III } \\ \text { e. } & \text { I } & \text { II } & \text { III }\end{array}$

3. Ali is an imaginative high school student, who tends toward concrete experience and reflective observations, and approaches things from different perspectives. According to Kolb, which of the following learning styles does Ali belong to?
a. Diverging
b. Converging
c. Assimilating
d. Accommodating
e. Visualising

4. "A teacher requested one student to perform emergency actions that should be taken when $\mathrm{s} /$ he feel an earthquake". What is the teaching method the teacher used in this case?
a. Lecture
b. Discussion
c. Brainstorming
d. Case study
e. Role playing

Author: Mustafa Koc PhD is an Associate Professor in the Department of Computer Education and Instructional Technologies and the Vice Dean of the College of Education, Suleyman Demirel University, Isparta, Turkey. His current research interests include technology integration in teacher education, collaborative and constructivist learning environments, educational uses of digital video, and technological cognitive tools. Email: mustafakoc@sdu.edu.tr

Please cite as: Koc, M. (2012). Pedagogical knowledge representation through concept mapping as a study and collaboration tool in teacher education. Australasian Journal of Educational Technology, 28(4), 656-670.

http: / / www.ascilite.org.au/ajet/ajet28/koc.html 